\title{
Structure and genetic diversity of Brazilian Zebu cattle breeds assessed by pedigree analysis
}

\author{
M.L. Santana Jr. ${ }^{\mathrm{a}, *}$, R.J. Pereira ${ }^{\mathrm{a}}$, A.B. Bignardi ${ }^{\mathrm{a}}$, D.R. Ayres ${ }^{\mathrm{a}}$, G.R.O. Menezes ${ }^{\mathrm{b}}$, L.O.C. Silva ${ }^{\mathrm{b}}$, \\ G. Leroy ${ }^{\text {c,d }}$, C.H.C. Machado ${ }^{\mathrm{e}}$, L.A. Josahkian ${ }^{\mathrm{e}}$, L.G. Albuquerque ${ }^{\mathrm{f}}$ \\ ${ }^{a}$ Grupo de Melhoramento Animal de Mato Grosso (GMAT), Instituto de Ciências Agrárias e Tecnológicas, Campus Universitário de Rondonópolis, Uni- \\ versidade Federal de Mato Grosso, MT-270, Km 06, CEP 78735-901 Rondonópolis, MT, Brazil \\ b Embrapa Gado de Corte, CEP 79106-550 Campo Grande, MS, Brazil \\ ' AgroParisTech, UMR1313 Génétique Animale et Biologie Intégrative, 16 rue Claude Bernard, F-75321 Paris 05, France \\ d INRA, UMR1313 Génétique Animale et Biologie Intégrative, Domaine de Vilvert, F-78352 Jouy-en-Josas, France \\ e Associação Brasileira dos Criadores de Zebu, CEP 38022-330 Uberaba, MG, Brazil \\ ${ }^{\mathrm{f}}$ Faculdade de Ciências Agrárias e Veterinárias, Universidade Estadual Paulista, CEP 14884-900 Jaboticabal, SP, Brazil
}

\section{A R T I C L E I N F O}

\section{Article history:}

Received 29 September 2015

Received in revised form

3 February 2016

Accepted 10 February 2016

Keywords:

Effective population size

Generation interval

Inbreeding

Zebu cattle

\begin{abstract}
A B S T R A T
The monitoring of population structure, inbreeding and other related parameters has great potential to prevent major losses of genetic diversity in populations of Zebu cattle in Brazil. Therefore, the objective of the present study was to investigate the structure and genetic diversity of Brazilian Zebu cattle breeds by pedigree analysis. The national pedigree file of the seven Brazilian Zebu breeds was used, which included all registered animals (12,290,243) born between 1938 and 2012: Brahman, Gir, Guzerá, Indubrasil, Nelore, Sindi, and Tabapuã. Almost all breeds studied undergo expansion in their census which, however, is not accompanied by the maintenance of genetic diversity. Problems were encountered in all breeds, but most of them can currently be considered less important. Using the calculation method considered as the most accurate for pedigree analysis when some population substructure exists, all breeds, except Sindi, had effective population size greater than 100 . The most common problems were the presence of tight bottlenecks in the pedigree, which were mainly due to the intensive use of few animals as parents and the high degree of population subdivision. The use of a wider range of sires is therefore recommended. However, most Zebu breeds can deal with breeding programs using high selection intensities. Greater care should be taken in the case of the Indubrasil breed since its census was reduced drastically over the last few years, a fact favoring the occurrence of serious problems related to inbreeding. Although Sindi presents problems due to subdivision and possesses a relatively small census compared to other Zebu breeds, this population would have a promising future if its breeding policy were revised.
\end{abstract}

(c) 2016 Elsevier B.V. All rights reserved.

\section{Introduction}

Zebu cattle breeds (Bos indicus) play an important role in meat and milk production in (sub)tropical countries, particularly in Brazil. An estimated $80 \%$ of the 210 million cattle raised in Brazil are pure or crossbred Zebu animals. The undeniable adaptation of Zebu breeds to high temperatures and low-quality pastures and their resistance to parasites strongly contributed to the extensive dissemination of these breeds in Brazil. Zebu cattle were first introduced in Brazil in 1875 through several imports that brought 6262 animals of Indian origin. The first animals were officially

\footnotetext{
* Corresponding author.

E-mail address: 10mario@gmail.com (M.L. Santana Jr.).
}

registered in 1938 when the herd book of Zebu Breeds was created. More than 12 million animals had been registered until 2012 , including 85.4\% Nelore, 4.4\% Gir, 3.8\% Tabapuã, 3.5\% Guzerá, 2.1\% Brahman, 0.7\% Indubrasil, and 0.2\% Sindi.

In Brazil, all Zebu breeds have been submitted or are being submitted to a genetic improvement process using methods such as BLUP, with some breeds being selected for milk, meat, or both. As a consequence, several of these breeds without an appropriate mating program can exhibit some degree of subdivision which, according to Cervantes et al. (2008, 2011) may increase inbreeding and consequently reduce genetic diversity at the individual level. The evaluation of genetic diversity, structure and gene flow based on pedigree data has been extensively used in different livestock species for conservation and breeding purposes. In the case of Zebu cattle, important studies based on pedigree analysis have been 
performed, but these studies are often restricted to subpopulations of a single breed (Malhado et al., 2009; Peixoto et al., 2010; Reis Filho et al., 2010). Practically all studies conducted on Zebu cattle in Brazil indicate problems such as a reduced effective size, bottlenecks in the pedigree, an increase in average inbreeding (Faria et al., 2009; Malhado et al., 2009; Peixoto et al., 2010), and even the risk of extinction (Carneiro et al., 2009). Therefore, the objective of the present study was to investigate the structure and genetic diversity of Brazilian Zebu cattle breeds by pedigree analysis.

\section{Material and methods}

\subsection{Breeds and pedigree data}

The national pedigree file of the seven Brazilian Zebu breeds was used, which included all registered animals $(12,290,243)$ born between 1938 and 2012: Brahman (BRA), Gir (GIR), Guzerá (GUZ), Indubrasil (IND), Nelore (NEL), Sindi (SIN), and Tabapuã (TAB) (Table 1). Pedigree data were obtained from the herd book of Zebu Breeds stored by the Brazilian Association of Zebu Breeders ( $A B C Z$ ), Uberaba, Minas Gerais, Brazil. The breeds studied differ in terms of selection purpose and formation. In general, the BRA, NEL and TAB breeds are selected for meat production, GIR selected for milk (mainly) or milk and meat, SIN selected for milk production, GUZ selected for meat, milk or both, and IND selected for meat (mainly) or meat and milk. The BRA is a Zebu breed developed in the United States from the cattle imported from India and Brazil. The breed was officially introduced in Brazil in 1994 by the importation of animals from the
United States. The GUZ, NEL, and GIR breeds had an important influence on formation of BRA. The IND breed was formed by crossings mainly between GIR and GUZ animals from 1930 to 1940. The TAB breed was formed around 1940 by crossings between polled cattle of European origin ('Mocho Nacional') and animals of Indian origin, mainly NEL, GUZ and GIR. As mentioned earlier, the GIR, GUZ, NEL and SIN breeds were introduced in Brazil mainly by imports from India. In the present study, no differentiation was made between polled and horned animals within each breed studied.

\subsection{Pedigree analysis}

The analyses were performed using the EVA (Berg et al., 2006), PEDIG (Boichard, 2002) with modifications made by Gregoire Leroy to compute effective population size based on coancestry, and CFC (Sargolzaei et al., 2006) softwares. All parameters were computed for the reference population of animals born from 2005 to 2012. This definition is equivalent to animals born in the last generation interval.

The number of equivalent complete generations (ECG) traced was computed as the sum over all known ancestors of the terms $\left(1 / 2^{d}\right)$, where $d$ is the ancestor's generation number, which is equal to one for the parents, two for the grandparents, etc. (Maignel et al., 1996). Effective population sizes were estimated on the basis of individual rates of inbreeding $\Delta F_{i}$ (González-Recio et al., 2007; Gutiérrez et al., 2009) and coancestry $\Delta C_{i j}$ (Cervantes et al., 2011), considering:

$\Delta F_{i}=1-\sqrt[t_{i}-1]{\left(1-F_{i}\right)}$

Table 1

Summary statistics of the pedigree analysis of the Brazilian Zebu breeds for individuals in the reference population (born between 2005 and 2012).

\begin{tabular}{|c|c|c|c|c|c|c|c|}
\hline \multirow[t]{2}{*}{ Item } & \multicolumn{7}{|l|}{ Breeds } \\
\hline & Brahman & Gir & Guzerá & Indubrasil & Nelore & Sindi & Tabapuã \\
\hline Entire pedigree & 260573 & 534664 & 425475 & 80596 & 10494715 & 24844 & 469376 \\
\hline Reference population & 185842 & 209215 & 176390 & 3744 & 4045548 & 12549 & 181523 \\
\hline ECG & 7.23 & 5.01 & 6.54 & 5.82 & 6.03 & 4.77 & 4.81 \\
\hline MAXG & 30 & 16 & 18 & 16 & 24 & 13 & 13 \\
\hline Average $F(\%)$ & 2.10 & 2.04 & 2.39 & 6.24 & 2.70 & 3.01 & 1.90 \\
\hline $\boldsymbol{F}=\mathbf{0}(\%)$ & 21.94 & 31.68 & 11.21 & 24.04 & 18.31 & 40.28 & 25.05 \\
\hline $0<F \leq 6.25(\%)$ & 70.87 & 58.73 & 79.28 & 39.64 & 74.67 & 26.88 & 67.52 \\
\hline $6.25<F \leq 12.5(\%)$ & 5.51 & 6.37 & 6.75 & 13.70 & 5.85 & 18.57 & 4.86 \\
\hline $12.5<F \leq 25(\%)$ & 1.46 & 2.64 & 2.27 & 19.55 & 0.89 & 12.53 & 2.09 \\
\hline$F>25(\%)$ & 0.22 & 0.58 & 0.49 & 3.07 & 0.27 & 1.74 & 0.47 \\
\hline Maximum F (\%) & 32.73 & 48.25 & 56.25 & 40.65 & 47.58 & 44.14 & 38.28 \\
\hline Average $C(\%)$ & 2.42 & 1.82 & 1.73 & 1.36 & 2.85 & 2.85 & 1.40 \\
\hline$\alpha$ & -0.40 & 0.20 & 0.64 & 4.40 & -0.03 & 1.96 & 0.45 \\
\hline $\mathrm{NeFi}$ & 158.5 & 104.1 & 118.1 & 40.3 & 100.23 & 37.4 & 101.5 \\
\hline $\mathrm{NeCi}$ & 151.5 & 138.6 & 192 & 199.6 & 113.33 & 84.2 & 169.2 \\
\hline$S$ & 0.96 & 1.33 & 1.63 & 4.95 & 1.13 & 2.25 & 1.67 \\
\hline ne & 21263 & 18912 & 9937 & 1720 & 418475 & 969 & 19080 \\
\hline fe & 281.90 & 96.10 & 119.00 & 169.20 & 37.00 & 43.00 & 89.10 \\
\hline$f a$ & 40.70 & 46.12 & 69.87 & 63.39 & 28.36 & 26.98 & 55.70 \\
\hline fg & 21.26 & 27.75 & 29.71 & 37.36 & 19.41 & 17.72 & 36.21 \\
\hline$f a / f e$ & 0.14 & 0.48 & 0.59 & 0.37 & 0.77 & 0.63 & 0.63 \\
\hline $\mathrm{fg} / \mathrm{fe}$ & 0.08 & 0.29 & 0.25 & 0.22 & 0.52 & 0.41 & 0.41 \\
\hline$G D^{*}-G D$ & 2.17 & 1.28 & 1.26 & 1.04 & 1.22 & 1.66 & 0.82 \\
\hline $1-G D^{*}$ & 0.18 & 0.52 & 0.42 & 0.30 & 1.35 & 1.16 & 0.56 \\
\hline 1-GD & 2.35 & 1.80 & 1.68 & 1.34 & 2.58 & 2.82 & 1.38 \\
\hline A25\% & 5 & 5 & 8 & 5 & 3 & 3 & 6 \\
\hline A50\% & 16 & 20 & 25 & 26 & 14 & 11 & 32 \\
\hline A75\% & 80 & 108 & 110 & 93 & 115 & 31 & 227 \\
\hline $1000 A(\%)$ & 87.29 & 90.57 & 93.60 & 99.79 & 83.37 & 100.00 & 85.11 \\
\hline
\end{tabular}

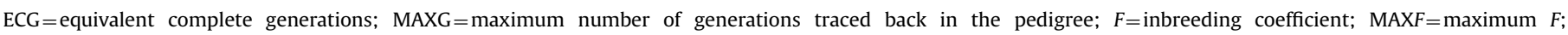

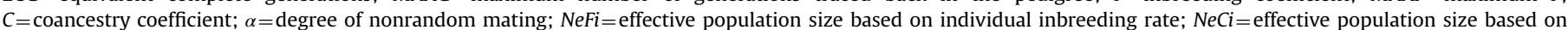

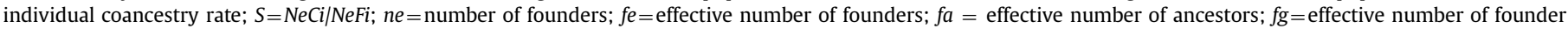

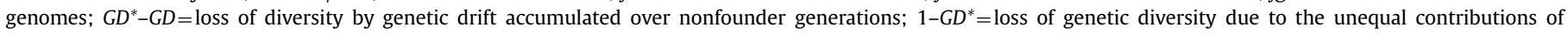

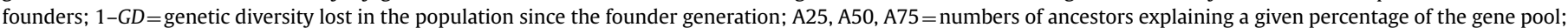
$1000 \mathrm{~A}=$ percentage of the gene pool explained by the first 1000 ancestors. 
$\Delta C_{i j}=1-\sqrt[\left(t_{i}+t_{j}\right) / 2]{\left(1-C_{i j}\right)}$

where $F_{i}$ is the inbreeding coefficient of individual $i, C_{i j}$ is the coancestry coefficient between individuals $i$ and $j$, and $t_{i}$ and $t_{j}$ are their respective ECG. Finally, the following formulas were used: $N e F_{i}=1 /(2 \overline{\Delta F})$ and $N e C_{i}=1 /(2 \overline{\Delta C})$. The number of equivalent subpopulations was computed as described by Cervantes et al. (2008): $\mathrm{S}=\mathrm{NeCi} / \mathrm{NeFi}$.

The degree of nonrandom mating was measured by the correlation of genes within individuals relative to the correlation of genes taken at random from the population $(\alpha)$ as done in the study of Caballero and Toro (2000). This coefficient gives an indication of the degree of deviation from Hardy-Weinberg proportions and is related to the previous inbreeding coefficients by $(1-F)=(1-C)(1-\alpha)$ (Wright, 1969). Inbreeding coefficients of animals born in each year were split into two parts called old (F_old) and new (F_new) inbreeding. New inbreeding was defined as the period of the three first generations and the old inbreeding resulted from the difference of the total inbreeding coefficient taking into account all pedigree information and new inbreeding of each animal. The contributions of nodal common ancestors to inbreeding, i.e., which form inbreeding loops, were computed according to Colleau and Sargolzaei (2008). The expected marginal contribution of each major ancestor $j$ was computed as its expected genetic contribution, independent of the contributions of the other ancestors (Boichard et al., 1997). The number of founders $\left(f_{e}\right)$ and ancestors $\left(f_{a}\right)$ was obtained to evaluate the concentration of the origin of both animals and genes. Parameter $f_{e}$ was defined as the number of equally contributing founders that would be expected to produce the same genetic diversity as observed in the population under study (Lacy, 1989). When founders contribute to the reference population more equally, the effective number of founders is higher. This parameter was calculated as $f_{e}=1 /\left[\sum_{k=1}^{f} q_{k}^{2}\right]$, where $q_{k}$ is the probability of gene origin of founder $k$. Parameter $f_{a}$ is the minimum number of ancestors, not necessarily founders, explaining the complete genetic diversity of a population. This parameter complements the information provided by the effective number of founders by accounting for the losses of genetic variability caused by the unbalanced use of breeding individuals producing bottlenecks. This parameter was calculated as $f_{a}=1 /\left[\sum_{j=1}^{a} q_{j}^{2}\right]$, where $q_{j}$ is the marginal contribution of ancestor $j$, which is the genetic contribution made by an ancestor that is not explained by other ancestors chosen before. The founder genome equivalents $\left(f_{g}\right)$ can be defined as the number of founders that would be expected to produce the same genetic diversity as observed in the population under study if the founders were equally represented and no loss of alleles occurred (Ballou and Lacy, 1995). Following Caballero and Toro (2000), parameter $f_{g}$ was obtained by the inverse of twice the average coancestry of the individuals included in a pre-defined reference population. The effective number of non-founders $\left(f_{n}\right)$ accounts for the effects of genetic drift in non-founder generations. This parameter was computed by the following expression proposed by Caballero and Toro (2000): $\frac{1}{f_{g}}=\frac{1}{f_{e}}+\frac{1}{f_{n}}$.

The genetic diversity (GD) in the reference population was computed as: $G D=1-\frac{1}{2 f_{g}}$ (Lacy, 1989, 1995). In domestic populations, bottlenecks and genetic drift occur frequently and lead to loss of genetic diversity. The genetic diversity lost in the population since the founder generation can be estimated by $1-G D$. The loss of genetic diversity due to unequal contributions of founders was estimated by $1-G D^{*}$, where $G D^{*}=1-\frac{1}{2 f_{e}}$ (Caballero and Toro, 2000). The difference between $G D$ and $G D^{*}$ indicates the loss of genetic diversity due to genetic drift that had accumulated since the founding of the population (Lacy, 1995). Thus, this difference can be expressed as: $G D^{*}-G D=\frac{1}{2 f_{n}}$.

The generation interval (GI) was defined as the average age of the parents at the birth of their progeny that were subsequently kept for reproduction. Average trends of GI were estimated by regressing means of GI of animals by birth year using all historical data available.

\section{Results}

\subsection{Pedigree completeness level, demographic parameters, and generation interval}

All Brazilian Zebu cattle breeds exhibited an increase in pedigree knowledge over the years as shown in Fig. S1. Notably, the equivalent complete generations (ECG) was higher in the BRA breed, with a value close to 8 in 2012. According to the number of ECG calculated for animals of the reference population, the level of pedigree knowledge was high for BRA, intermediate for GUZ, IND and NEL, and low for GIR, SIN and TAB (Table 1). The maximum number of generations traced reached the highest values in BRA (30) and NEL (24), intermediate values in GIR, GUZ and SIN (1618), and the lowest values in SIN and TAB (13) (Table 1). The number of animals born per year has been increasing in most breeds, particularly after 2000, except for IND (Fig. S1). In the latter case, fewer than 300 animals had been registered in 2012, while this number ranged from approximately 1700 (SIN) to 347,000 (NEL) animals for the other breeds. In the IND breed, a reduction in the number of records of approximately $63 \%$ has been observed in the last decade alone.

The average generation interval (AGI) in Zebu breeds ranged from 6.95 (BRA) to 9.78 years (IND), as shown in Table 2. The trend in annual change in AGI using all historical data available was positive for all breeds, with an estimated annual increase of 2.43 (BRA) to 12.17 days (IND). The AGI for different pathways (sireprogeny, dam-progeny, sire-son, sire-daughter, dam-son, and dam-daughter) were almost always longer for IND (Table 2). The sire-progeny AGI (7.14-11.36 years) was always longer than the dam-progeny AGI (5.20-7.96 years) for all breeds. As expected, the age of sires and dams at reproduction was also higher for IND, followed by GIR, NEL, GUZ, TAB, SIN, and BRA. The percentage of breeding sires with more than 10 or 15 years was consistently higher in the IND breed. The percentage of breeding dams with more than 10 or 15 years was higher in the GIR breed. The percentage of registered males was lower in the SIN and GIR breeds. In GIR, the percentage of registered females accounted for almost $60 \%$ of all registered animals. The cow to bull ratio was much higher in NEL (31.82), followed by TAB (22.77), BRA (17.23), and GUZ (15.46). The number of cows per bull ranged from 8 to 11 in the GIR, IND, and SIN breeds.

\subsection{Inbreeding, coancestry, and effective population size}

The average inbreeding coefficient ranged from $2 \%$ to $3 \%$ in most of the breeds studied, except for the IND breed in which the inbreeding coefficient was higher than $6 \%$ (Table 1). The percentage of non-inbred animals ranged from $11 \%$ (GUZ) to about $40 \%$ (SIN). The percentage of animals with an inbreeding coefficient higher than $25 \%$ was much higher in IND (3.07\%) and SIN (1.74\%) than in the other breeds $(0.22-0.58 \%)$. Mean coancestry was higher for the BRA, NEL and SIN breeds (2.42-2.85\%). As can be seen in Fig. 1, average inbreeding has been increased over the years in some of the breeds studied. In the GIR breed, average inbreeding had increased considerably until 1998, reaching a value of 3.55 in 1998 and decreasing markedly thereafter. Similarly, the 
Table 2

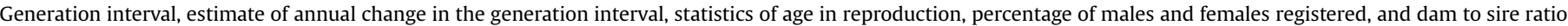
of the Brazilian Zebu breeds for individuals in the reference population (born between 2005 and 2012).

\begin{tabular}{|c|c|c|c|c|c|c|c|}
\hline \multirow[t]{2}{*}{ Item } & \multicolumn{7}{|l|}{ Breeds } \\
\hline & Brahman & Gir & Guzerá & Indubrasil & Nelore & Sindi & Tabapuã \\
\hline AGI & 6.95 & 8.93 & 7.60 & 9.78 & 7.93 & 7.01 & 7.20 \\
\hline TREND $^{\mathrm{a}}$ & $2.43^{* *}$ & $8.52^{* *}$ & $4.87^{* *}$ & $12.17^{* *}$ & $6.08^{* *}$ & $4.87^{*}$ & $7.30^{* *}$ \\
\hline AGI Sire-progeny & 8.39 & 10.65 & 8.29 & 11.36 & 8.91 & 7.14 & 7.66 \\
\hline AGI Dam-progeny & 5.20 & 7.03 & 6.86 & 7.96 & 6.73 & 6.87 & 6.65 \\
\hline AGI Sire-son & 9.82 & 13.79 & 9.18 & 11.47 & 9.99 & 6.80 & 8.34 \\
\hline AGI Sire-daughter & 9.06 & 10.95 & 8.07 & 10.91 & 8.93 & 7.10 & 7.41 \\
\hline AGI Dam-son & 5.10 & 7.53 & 7.34 & 9.92 & 6.54 & 6.92 & 6.61 \\
\hline AGI Dam-daughter & 4.99 & 7.51 & 6.87 & 8.54 & 6.72 & 7.37 & 6.52 \\
\hline AS (years) & 5.95 & 7.06 & 6.93 & 9.38 & 6.65 & 6.13 & 6.22 \\
\hline AD (years) & 6.51 & 8.80 & 7.35 & 9.95 & 7.98 & 6.49 & 7.09 \\
\hline S10 (\%) & 13.74 & 19.04 & 18.41 & 25.68 & 15.57 & 12.55 & 13.54 \\
\hline D10 (\%) & 19.32 & 42.19 & 28.54 & 23.37 & 33.48 & 19.74 & 26.79 \\
\hline S15 (\%) & 5.40 & 7.95 & 6.25 & 15.80 & 4.18 & 1.81 & 3.80 \\
\hline D15 (\%) & 2.63 & 6.66 & 3.47 & 5.15 & 3.81 & 1.21 & 1.55 \\
\hline Males (\%) & 51.29 & 40.21 & 49.88 & 49.69 & 50.48 & 46.19 & 51.18 \\
\hline Females (\%) & 48.71 & 59.79 & 50.12 & 50.31 & 49.52 & 53.81 & 48.82 \\
\hline $\mathrm{D} / \mathrm{S}$ & $17.23 / 1$ & $11.78 / 1$ & $15.46 / 1$ & $8.00 / 1$ & $31.82 / 1$ & $10.22 / 1$ & $22.77 / 1$ \\
\hline
\end{tabular}

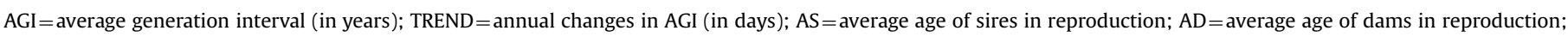
$\mathrm{S} 10, \mathrm{~S} 15, \mathrm{D} 10, \mathrm{D} 15=$ percentage of sires or dams with more than 10 or 15 years in reproduction; $\mathrm{D} / \mathrm{S}=$ dam to sire ratio.

a Significance levels for linear solutions denoted by ${ }^{* *}(P<0.01)$. Data used in these specific calculations included all historical data available for each breed.

SIN breed had the highest average inbreeding in 2001 (11.42\%), followed by a sudden decrease. In the GUZ and NEL breeds, a reduction in average inbreeding was observed by 2003 and an increase in the following years. In the case of the IND breed, there was a consistent increase in the average level of inbreeding until 2000 , followed by fluctuations in the last decade. Over the last few years, mean coancestry has exceeded or is close to exceeding average inbreeding in the BRA, GIR, NEL, SIN, and TAB breeds (Fig. 1). The averages of F_old and F_new as percentage of the total inbreeding were 24 and $73 \%$ (BRA), 12 and $88 \%$ (GIR), 17 and $83 \%$ (GUZ), 12 and 88\% (IND), 8 and 92\% (NEL), 7 and 88\% (SIN), 6 and 94\% (TAB), respectively. For all breeds, the F_new has been reduced over the years (Fig. 2). BRA was the breed with lower level of F_new. GUZ was the breed with the highest reduction of F_new. Only in the 2000s, SIN showed a important divergence between F_new and F_old. SIN showed the highest peaks of increase in inbreeding, followed by IND and GIR. In contrast, BRA showed a smaller increase in inbreeding over the years.

The $\mathrm{NeCi}$ ranged from 84.2 (SIN) to 199.6 (IND), whereas $\mathrm{NeFi}$ almost always presented lower values ranging from 37.4 (SIN) to 158.5 (BRA) (Table 1). The $S$ was higher in IND (4.95) and much lower in BRA (0.96). As shown in Fig. 3, NeCi had decreased or had remained constant in most breeds in recent years, except for the SIN breed that showed a substantial increase over the last 20 years. In contrast, $\mathrm{NeFi}$ tended to increase in most breeds over the last few years.

\subsection{Population structure, breeding policy, and degree of nonrandom mating}

The $S$ assumed high values of 8-10 in the BRA, GIR, GUZ, and IND breeds at different times during the history (Fig. 3). However, in most breeds the value of $S$ has stabilized or has begun decreasing in recent years. Thus, in the last decade, breeding policies of the studied breeds tended to avoid the subdivision. In BRA, it is observed that practically all animals are equally likely to mate with any individual of the opposite sex ( $S$ very close to 1 in recent years). GIR, GUZ, and IND showed breeding policy predominantly intra-herd between 1970 and early 2000s. NEL, TAB, and particularly SIN, showed breeding policy based on the abusive use of some individuals as breeding animals. The degree of nonrandom mating was higher for IND (4.4\%) and SIN (1.96\%) than for the other breeds. In all breeds (except for IND), the degree of nonrandom mating tended to decrease or was close to zero in the last decade (Fig. 1).

\subsection{Probabilities of gene origin and loss of genetic diversity}

The NEL and SIN breeds exhibited the lowest values of $f e, f a$, and $f g$ (Table 1). The fe was much higher in BRA (281.9) than in any other breed. The $f a$ was lower in SIN (26.98) and higher in GUZ (69.87). In contrast, $f g$ was lower in SIN (17.72) and higher in IND (37.36). Thus, in the case of Brazilian Zebu cattle breeds, 17.7237.36 unrelated founder genomes would be necessary to explain the genetic diversity observed in the respective reference populations of each breed. Analysis of the values of $\mathrm{fa} / \mathrm{fe}$ and $\mathrm{fg} / \mathrm{fe}$ showed the presence of bottlenecks in the pedigree of all breeds, with these values ranging from 0.08 (BRA) to 0.77 (NEL). The loss of genetic diversity due to genetic drift accumulated over nonfounder generations $\left(G D^{*}-G D\right)$ was more important than the loss due to unequal contribution of founders $\left(1-G D^{*}\right)$ in almost all breeds, corresponding to $92.34,71.11,75.0,77.61,47.29,58.87$ and $59.42 \%$ in BRA, GIR, GUZ, IND, NEL, SIN and TAB, respectively (Table 1). For animals belonging to the reference population, the loss of genetic diversity since the founder generation $(1-G D)$ did not reach 3\%. However, as can be seen in Fig. 4, the loss of genetic diversity tends to increase in the next few years. The trends observed for $f e, f a$, and $f g$ are a reduction in almost all breeds. In the SIN and NEL breeds, the estimates of these parameters did not undergo a marked reduction in the last 5 years (Fig. 4).

\subsection{Contributions of ancestors to the gene pool and to inbreeding}

Few ancestors were responsible for a high percentage of the gene pool, e.g., 11-32 ancestors explained $50 \%$ of the gene pool of the reference population of all breeds (Table 1). Table S1 shows the genetic contributions and contributions to inbreeding of the five main ancestors of each breed. The cumulative marginal genetic contribution of these ancestors was 27.58, 26.01, 19.09, 21.58, 34.92, 34.91 and 23.10\% in BRA, GIR, GUZ, IND, NEL, SIN and TAB, 

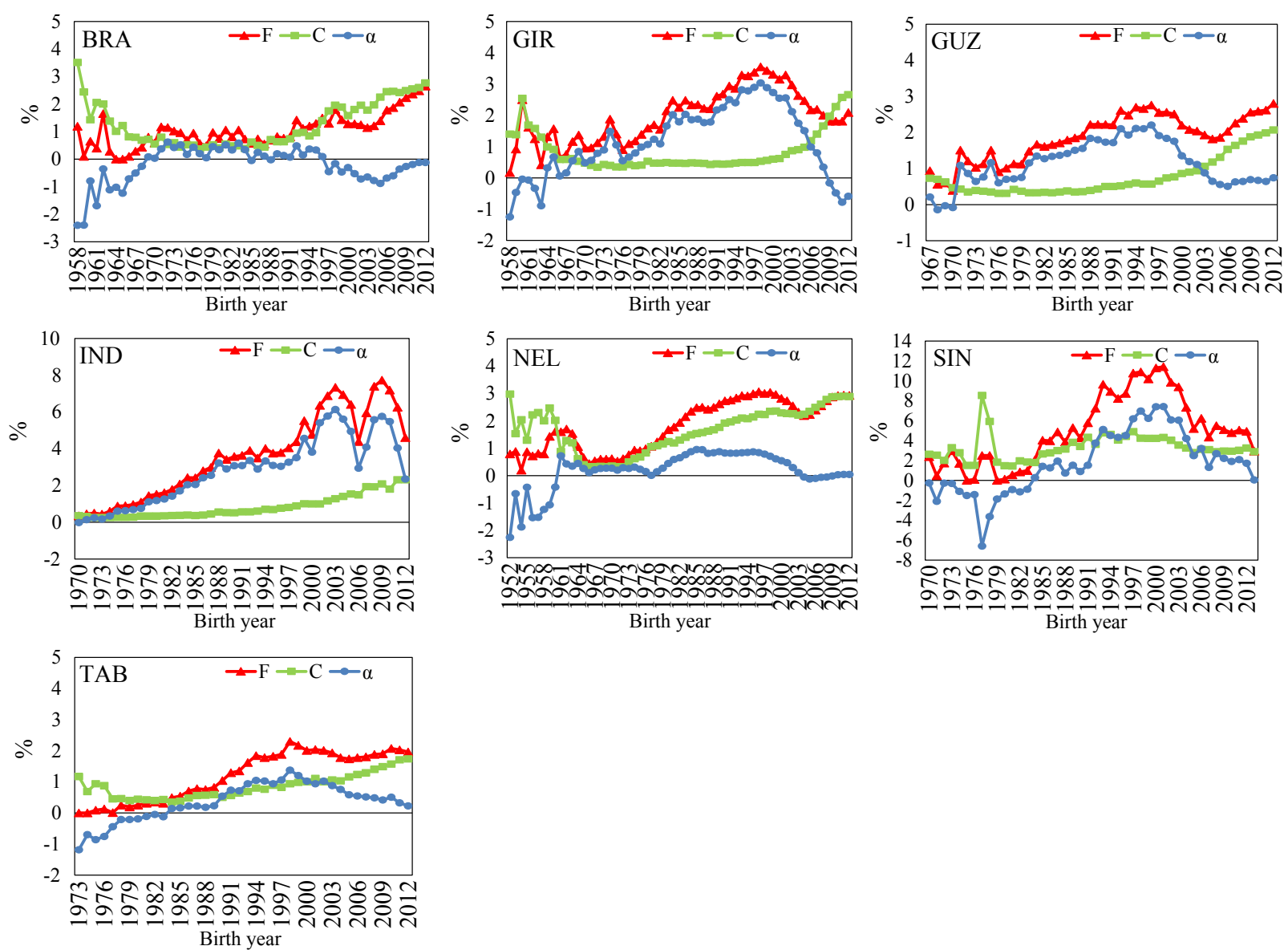

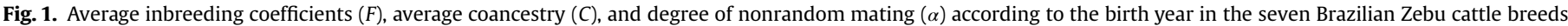
(BRA, Brahman; GIR, Gir; GUZ, Guzerá IND, Indubrasil; NEL, Nelore; SIN, Sindi; TAB, Tabapuã).

respectively. For BRA, $82.52 \%$ of the gene pool in recent years is due to foreign ancestors (United States, 73.41\%; Paraguay, 4.43\%; Argentina, 3.62\%; Colombia, 0.53\%; Australia, 0.53\%). The average year of birth of the five main ancestors was 1990, 1984, 1984, 1988, 1963, 1931 and 1987 in BRA, GIR, GUZ, IND, NEL, SIN and TAB, respectively. As can be seen in Table S1, 14.11 (IND) to 53.57\% (NEL) of the total inbreeding of animals belonging to the reference population can be explained by the five ancestors with major marginal genetic contribution in each breed. Karvadi IMP. (NEL), Vinculo da Prog. (TAB), Laguno (SIN), and JDH Remington Manso (BRA) alone contributed to $31.08,22.34,20.63$ and $19.67 \%$ of inbreeding in recent years in their respective populations.

\section{Discussion}

Pedigree knowledge has increased annually in all Zebu breeds studied (Fig. S1, Table 1). BRA was the Zebu breed that presented the best known pedigree (number of ECG of 7.23 and maximum number of generations traced of 30). This finding is probably due to the fact that this breed was imported from the United States where the herd book was established in 1924 (years before the creation of the herd book of Zebu breeds in Brazil). The SIN and $\mathrm{TAB}$ breeds presented the lowest level of pedigree knowledge among the breeds studied (Table 1). However, the number of ECG in these breeds has increased almost linearly over the last few years (Fig. S1). The number of animals born has also increased considerably in all breeds, except for IND (Fig. S1). A drastic reduction in the number of IND animals born has also been reported by Vercesi et al. (2002a) for the IND breed and by Carneiro et al.
(2009) for IND cattle from northeastern Brazil. According to the latter authors, the reduction in the IND breed mainly reflects the disinterest of breeders. This disinterest may be associated with a greater interest in other breeds or with the more frequent use of IND animals for purposes of crossing.

The AGIs obtained here were similar to those reported by Faria et al. (2001) for SIN (7.96 years), by Faria et al. (2009) for NEL, GIR and GUZ between 1994 and 1998 (about 8 years), by Reis Filho et al., (2010) for animals of the Dairy Gir subpopulation (8.25 years), by Peixoto et al. (2010) for a GUZ subpopulation selected for milk production (7.48 years), and by Caires et al. (2012) for TAB (7.3 years). Notably, the generation intervals were always longer for IND animals, reflecting the problems related to the drastic reduction in the census of this breed in recent years, which delays the replacement of animals in the herds. Vercesi et al. (2002a) obtained an AGI of 7.45 years for the IND breed between 1994 and 1998, while the current AGI of this breed was 9.78 years (Table 2). From the point of view of genetic improvement of the breed, this strong trend could be a matter of concern since the genetic progress of this population may be slower. A significant trend towards an increase of AGI over the years studied was observed in all Zebu breeds, demonstrating the low utilization of young sires despite the existence of incentive programs from some Brazilian institutions. Since breeding programs exist for most Zebu breeds, this trend can somehow be compensated by the use of elite sires with high accuracy. In terms of conservation of genetic diversity, long AGI prevent the rapid accumulation of inbreeding and genetic drift. The AGIs were more influenced by longer sire-progeny intervals. According to Santana et al. (2014), this is the result of the use of elite/famous sires with high accuracy as fathers of the next 

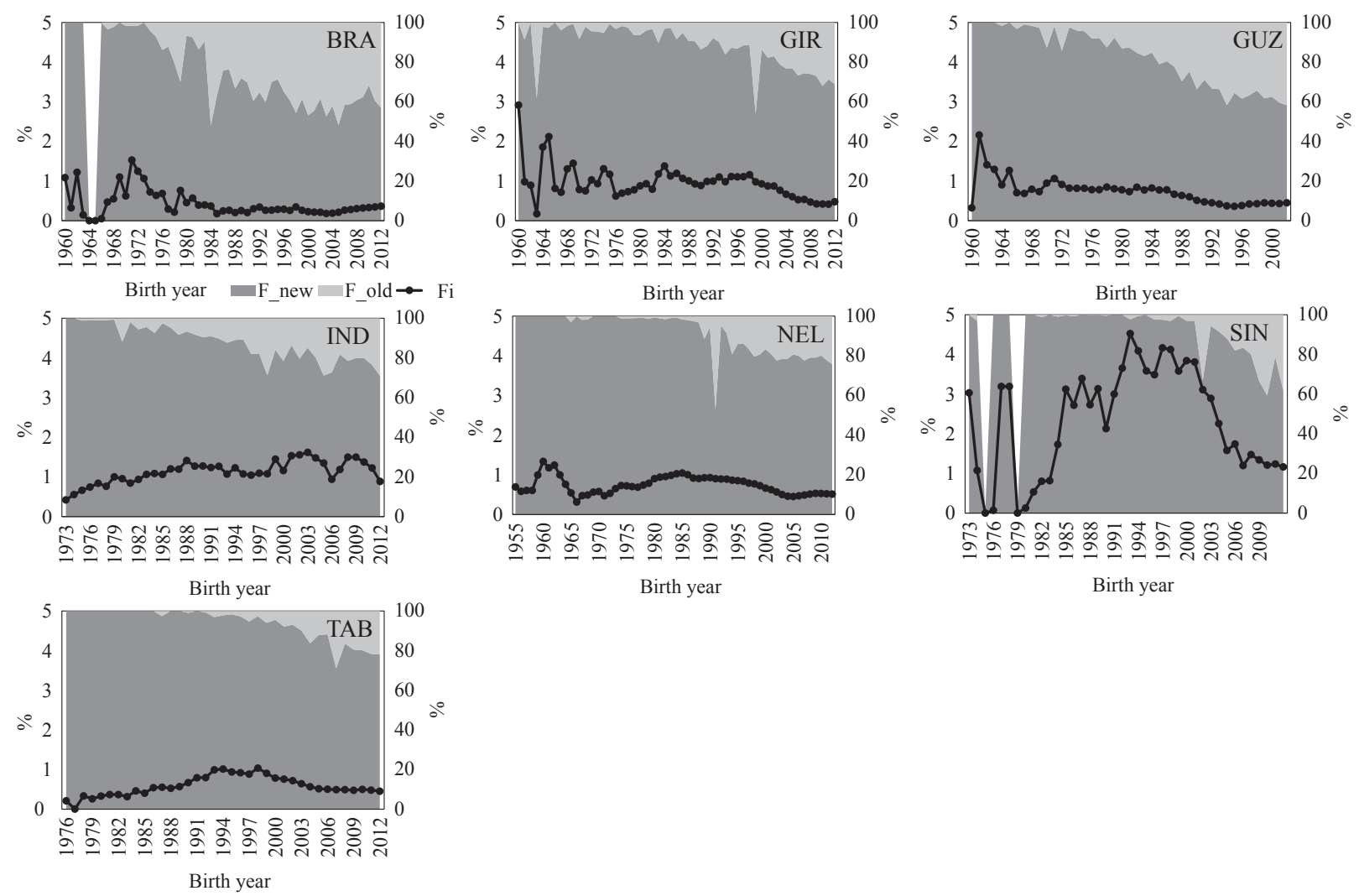

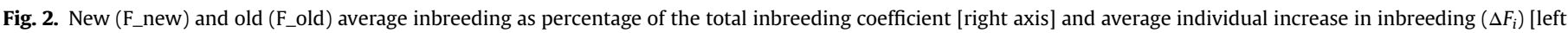

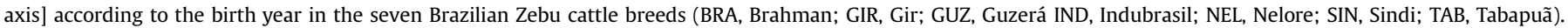

generation. Except for SIN, all breeds had longer sire-son AGI, demonstrating the slow replacement of males. The use of females older than 10 years as dams was more evident in GIR, since an important proportion of this population is selected mainly for milk production and cows therefore tend to remain for a longer period of time in their respective herds. The breeds containing a higher proportion of registered females were those used mainly for milk production (GIR and SIN). This may be evidence of selective registration of animals and use of sexed semen. The cow/bull ratio varied widely from one Zebu breed to the other. This finding was due in part to differences in reproductive management, the use of reproductive biotechnologies, and the selection intensity imposed.

Average inbreeding in the BRA breed was much higher than that reported by Faria et al. (2010) (0.49\%); however, these authors used records of only 8560 animals from 2002 to 2005. According to Perez O'Brien et al., (2015), BRA exhibited a moderate taurine ancestry which is consistent with the known taurine introgression during the formation of the breed. This finding helps to explain lower levels of inbreeding over the first years after the arrival of this breed in Brazil. In contrast, Perez O'Brien et al., (2015) concluded that NEL and GIR populations are of almost pure indicine ancestry regarding their autosomal genome. For BRA, there was a trend towards an increase in the average level of inbreeding, parallel to the increase in mean coancestry seen over the last few years (Fig. 1). As a consequence, the degree of nonrandom mating in this breed has been negative for more than a decade, but tended to increase over the last few years. As shown in Table 1 (animals belonging to the reference population), BRA showed one of the lowest degrees of subdivision (value of $S$ close to 1 ) among the populations studied and, logically, the estimates of effective population size (NeFi and $\mathrm{NeCi}$ ) were similar in recent years. The effective population sizes obtained here for the BRA reference population were lower than that reported by Faria et al. (2010)
(184). However, these estimates can vary widely depending on the method used for the calculation of effective population size (Leroy et al., 2013). For pedigree analysis of domestic populations in wich the pedigrees are minimally depth, exist higher or lower degree of subdivision, and when the objective is to modify the population substructure, Leroy et al. (2013) (and comments made by Goyache et al.) recommended the use of effective size based on coancestry (NeCi). In the study of Faria et al. (2010), the effective population size of the BRA breed was calculated based on the inbreeding rate between two successive generations.

In the GIR breed, the current average inbreeding (Table 1) was lower than that observed by Faria et al. (2009) for animals born between 1994 and 1998 (2.28\%) and by Reis Filho et al. (2010) for animals of the Dairy Gir subpopulation born between 1966 and 2003 (2.82\%). The degree of nonrandom mating in the GIR breed decreased drastically after 1998 (Fig. 1), probably as a result of the increase in genetic exchanges between herds (dual purpose and milk) and of the more intensive use of sires derived from the milk breeding program as indicated by Santana et al. (2014). This fact can also be confirmed by the observation of a reduction in the number of equivalent subpopulations (Fig. 3). A decrease in the average level of inbreeding and an increase in coancestry were observed in the GIR breed during the same period. Consequently, $\mathrm{NeFi}$ tended to increase and $\mathrm{NeCi}$ decreased. The effective population sizes reported in the literature are calculated mainly for regional samples or GIR subpopulations using methods based on the inbreeding rate between successive generations, sex ratio or even variance of progeny size, a fact impairing appropriate comparisons with the results obtained here. Among more recent studies, Reis Filho et al. (2010), studying the Dairy Gir subpopulation, reported an effective population size close to 100 for animals born between 2002 and 2003.

The average inbreeding in the GUZ breed tended to increase. 

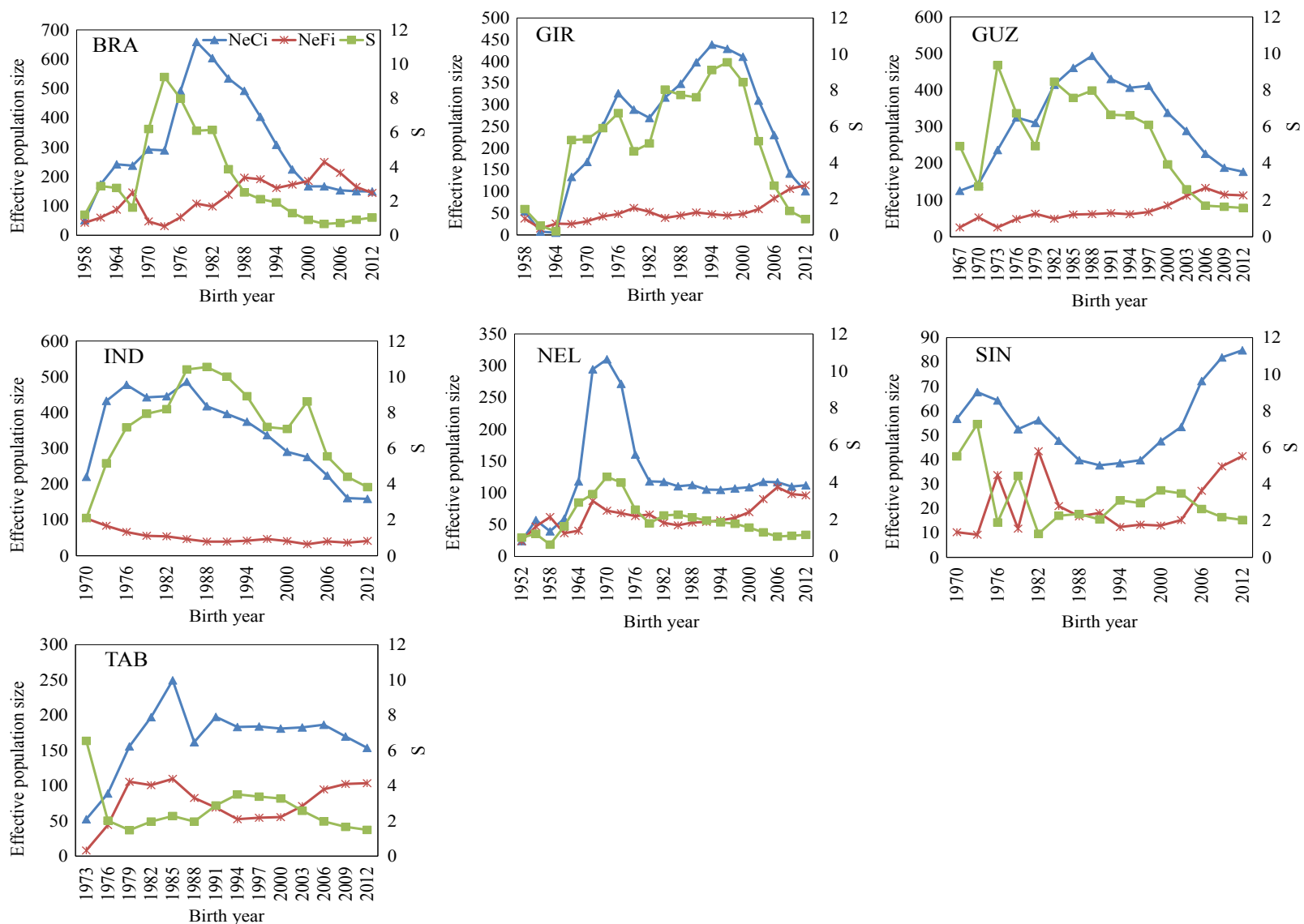

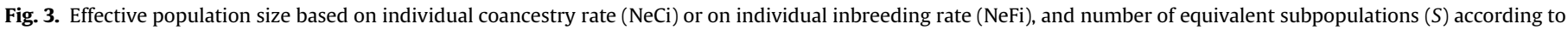
the birth year in the seven Brazilian Zebu cattle breeds (BRA, Brahman; GIR, Gir; GUZ, Guzerá IND, Indubrasil; NEL, Nelore; SIN, Sindi; TAB, Tabapuã).

The same was observed for mean coancestry. Faria et al. (2009) also found a trend towards an increase in the average level of inbreeding in GUZ cattle between 1979 (0.64\%) and 1998 (1.37\%). The degree of nonrandom mating in this breed showed a slight trend towards an increase in recent years (Fig. 1), while the number of equivalent subpopulations remained practically constant (Fig. 3). As a possible result of the establishment of the Breeding Program in GUZ at around 1994, the massive use of artificial insemination may have contributed to the reduction of inbreeding and population subdivision between 1997 and 2003. Nevertheless, the GUZ population is currently structured, a finding that can be explained by the subdivision of the population into herds selected for milk or meat, or both. Matings in this population still occur most frequently within subpopulations, groups of herds with similar breeding policy and breeding goals. The effective population sizes in the GUZ breed tended to be similar over the last few years (Fig. 3) as a result of the approximation observed between inbreeding and coancestry values (Fig. 3). The NeFi obtained here (Table 1) was similar to that reported by other authors for different periods (Faria et al., 2009; Peixoto et al., 2010).

The average inbreeding in recent years was much higher for the IND breed compared to the other Zebu breeds studied (Table 1). In IND, inbreeding as well as coancestry and the degree of nonrandom mating tended to increase over the years, and inbreeding was always higher than coancestry (Fig. 1). However, fluctuations in average inbreeding and in the degree of nonrandom mating were observed, whereas coancestry remained relatively stable. According to Cervantes et al. (2011) and Leroy et al. (2013), inbreeding is a parameter that is sensitive to pedigree knowledge and can be greatly affected by the subdivision of a population. As shown in Fig. S1, there was a certain irregularity in the number of ECG in the
IND breed over the last few years and, according to Fig. 3, IND is a highly structured population. Although it can also be a sampling effect related to the reduction in the population size, the drastic reduction (Fig. S1) probably also contributed to the decrease in the number of equivalent subpopulations seen in recent years (Fig. 3), since part of the herds of the breed ceased to exist or simply do no longer register their animals. Taken together, these factors resulted in the maintenance of $\mathrm{NeFi}$ at a lower level and in a consistent reduction of $\mathrm{NeCi}$ (Fig. 3). Vercesi et al. (2002a) obtained an effective population size based on the inbreeding rate between two successive generations of 40 between 1984 and 1998 (Table 1; Fig. 3). In contrast, Carneiro et al. (2009) reported an effective population size based on the inbreeding rate between two successive generations of 26 between 1998 and 2000 for the IND subpopulation from the northeastern region of Brazil. These different estimates demonstrate that the higher level of inbreeding in this breed is a historical problem and that little has been done so far to reverse this situation. In contrast to the low estimate of $\mathrm{NeFi}$, $\mathrm{NeCi}$ was much higher in recent years (about 200) (Table 1). Therefore, since IND is a highly structured population, $\mathrm{NeCi}$ would be the most indicated parameter to infer on the true status of genetic diversity in this population. On the basis of $\mathrm{NeCi}$, the possible loss of genetic diversity in this population would be a secondary problem in view of the reduction in its census and intensive use of matings within subpopulations. In the IND case, we do not reject the hypothesis that there is a Wahlund effect due to limited exchange of breeding animals across herds.

Similar to GIR, in NEL, SIN and TAB, coancestry has exceeded or tends to exceeds average inbreeding in recent years, parallel to a reduction or maintenance of the degree of nonrandom mating close to zero (Fig. 1). NEL cattle are the most successful beef cattle 

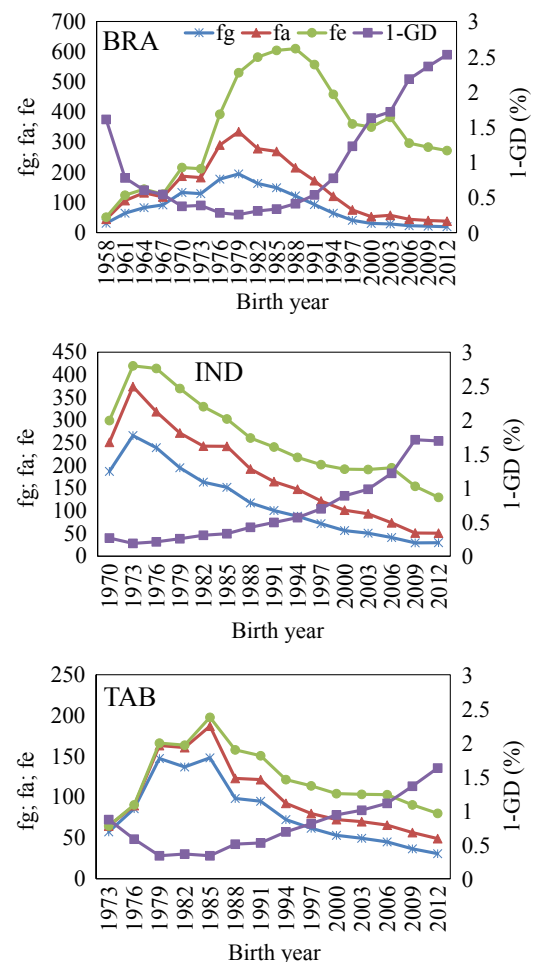
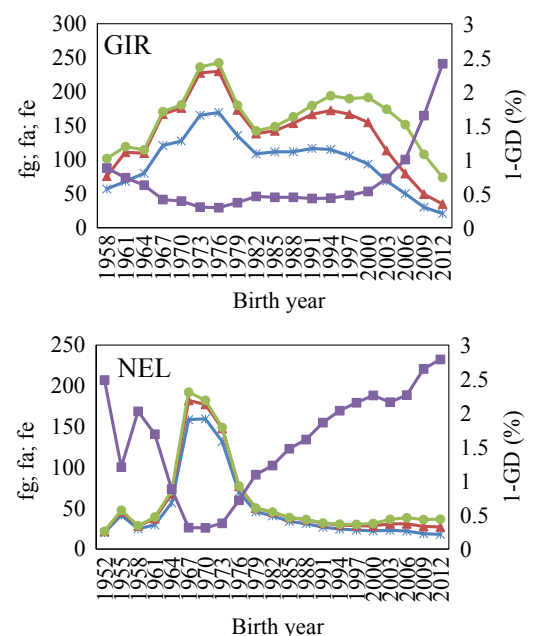

Birth year
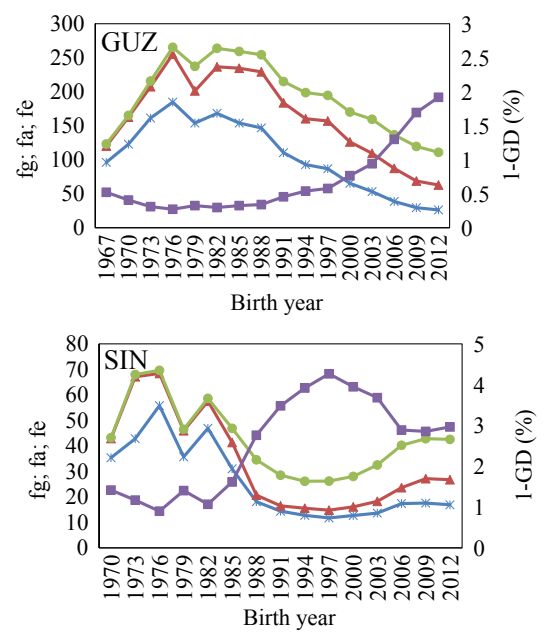

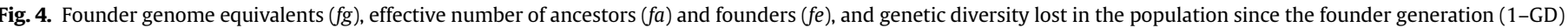
according to the birth year in the seven Brazilian Zebu cattle breeds (BRA, Brahman; GIR, Gir; GUZ, Guzerá IND, Indubrasil; NEL, Nelore; SIN, Sindi; TAB, Tabapuã).

breed in Brazil and constant expansion of the breed is expected. In this respect, genetic evaluation programs based on BLUP have been established for this breed as well as wide use of AI. The average level of inbreeding in NEL has been under relative control for at least three decades, as indicated by the finding that the mean $\mathrm{F}$ was almost always less than 3\% (Fig. 1). On the basis of the number of equivalent subpopulations, the NEL population is found to be weakly structured (Table 1 ). This also reinforces the idea that there is extensive genetic exchange across herds in NEL. Despite the existence of different herds restricted to polled animals, matings do not always occur within subpopulations. The effective population sizes of the NEL breed differed widely between 1964 and 1976, probably because of less pedigree knowledge, the smaller number of registered animals at that time, and the greater subdivision of the population (Fig. 3). In subsequent years, $\mathrm{NeCi}$ remained practically constant and always at a higher level than NeFi. The NeFi has remained relatively constant for many years and has increased in recent years probably because of the small reduction in the average level of inbreeding observed in the NEL breed between 2000 and 2009 (Fig. 3). The period after 2000 was characterized by a degree of nonrandom mating of practically zero and by a number of equivalent subpopulations close to 1 (Fig. 1).

An interesting observation in the SIN breed was the drastic reduction of average inbreeding in the last decade, as well as of the degree of nonrandom mating (Fig. 1). The registration of purebred SIN by the Brazilian Association of Zebu Breeders was stopped due to technical reasons between 1974 and 2001. This may have favored the inclusion of new founders (individuals without parent known) in the official herd book. Both $\mathrm{NeFi}$ and $\mathrm{NeCi}$ were lower than the estimates of these parameters for the other Zebu breeds (Table 1); however, these parameters showed an important increase over the last few years influenced by the recent reduction of inbreeding and coancestry (Figs. 1 and 3). Despite the recent reduction in the number of equivalent subpopulations, SIN continues to be one of the most structured Zebu breeds in Brazil (Table 1; Fig. 3). On the other hand, the reduction in the parameters cited above demonstrates a certain change in the management of matings within the breed over the last few years. The SIN population should continue to suffer changes in parameters such as inbreeding and also in its structure, considering the implementation of a progeny test in 2011 and the fact that semen commercialization increased by about 265\% over 2010-2012 according to Brazilian Association of Artificial Insemination. All of these factors should promote a greater genetic exchange between herds of this breed in the coming years.

In the $\mathrm{TAB}$ breed, $\mathrm{NeFi}$ and $\mathrm{NeCi}$ were much higher than the estimate obtained by Vercesi et al. (2002b) between 1994 and 1998 (55). The divergences between these estimates are mainly due to differences in the methods used to calculate the effective population size, the period studied, and the amount of information used. In contrast, there was agreement between the average inbreeding reported by Vercesi et al. (2002b) (1.6\% between 1994 and 1998) and the estimate obtained for the current reference population (1.9\%). The fact that the TAB breed was formed in Brazil by crossings between Zebu breeds and breeds of European origin, in addition to the lesser knowledge of its pedigree, may have favored the lower inbreeding coefficient and mean coancestry obtained when compared to the other breeds (Table 1). Although the number of equivalent subpopulations has decreased in recent years, TAB continues to be a structured population (Table 1, Fig. 3).

$A$ reduced number of genome equivalents and effective number of ancestors and founders in Zebu breeds has been reported by Faria et al. (2002) for the period from 1994 to 1998 for GIR (132, 211 , and 284 , respectively), $\operatorname{IND}(65,107$, and 180$), \operatorname{NEL}(26,34$, and $38)$, SIN (7, 9, and 16), and TAB (61, 78, and 111). Except for the SIN breed, all estimates reported by Faria et al. (2002) were lower than those obtained in the present study. According to these authors, the intensive use of few individuals as breeding animals was a major cause for the reduced estimates of the parameters cited above. Zavarez et al. (2015) invetigated the distribution of autozygosity levels based on runs of homozygosity of NEL cows and concluded that the signatures of selection were also probably 
related to the recent massive use of few sires. The disproportion between the effective number of ancestors and founders and between the number of genome equivalents and effective number of ancestors demonstrates the bottlenecks present in the pedigree of all breeds studied. In NEL, which is the largest census breed, the bottlenecks were less severe, while in BRA the bottlenecks were very tight. Similarly, Faria et al. (2009) observed less tight bottlenecks in NEL when compared to GIR and GUZ. Perez et al., (2014a, 2014b) founded higher rates of linkage disequilibrium decay for GIR than NEL. In agreement with the results obtained here, these differences were probably related to the selection goals (Perez et al., 2014a), NEL is a beef breed and GIR is a dairy breed, and events such as the rapid expansion of population and the reduction in the effective population size due to bottlenecks (Reich et al., 2001 ) as observed for GIR breed.

Loss of genetic diversity occurred to a greater or lesser extent in all Zebu breeds studied (Table 1, Fig. 4). Similarly, Santana et al. (2014) observed loss of genetic diversity of 2.3\% in the GIR breed until 2010. Genetic drift accumulated on non-founder generations was the main cause of loss of genetic diversity in all breeds. The same has been reported by Santana et al. (2014) for GIR cattle. According to Lacy (1995) and Caballero and Toro (2000), the mating of animals based on minimum coancestry in the next generation would maximize genetic diversity. Therefore, minimum coancestry matings would be recommended for all Zebu breeds studied.

Few ancestors explained an important percentage of the gene pool of the populations (Tables 1 and S1). This finding has been documented for different Zebu cattle populations (Vercesi et al., 2002a; Peixoto et al., 2010; Reis Filho et al., 2010). Over the years, an important proportion of the gene pool has been explained by an increasingly smaller number of ancestors in some Zebu breeds. Faria et al. (2009) found that the marginal genetic contribution of a single ancestor reached $3.1 \%$ and $4.1 \%$ in GIR and GUZ, respectively, between 1994 and 1998. In the present study, these values were $9.23 \%$ and $5.42 \%$, respectively. This demonstrates an unbalanced contribution of ancestor to the gene pool of Zebu breeds. As a consequence, matings should be managed carefully in order to avoid problems related to inbreeding. The contribution of the most influential ancestors to inbreeding was high in TAB, SIN, BRA, and especially in NEL, in which only two ancestors contributed to practically $43 \%$ of total inbreeding. This high contribution has also been documented by Stachowicz et al. (2011) for Canadian Holstein and Jersey cattle and by Santana et al. (2014) for GIR cattle. According to these authors, the high contributions to inbreeding are mainly due to the intensive use of elite ancestors and their descendants, which is reflected in a small effective number of genome equivalents.

BRA was the breed with lower level of F_new (Fig. 2). Thus, the inbreeding generated in their country of origin (until 1994) can be even more important than that in other breeds studied. This result is consistent with the trend of slight increase in inbreeding rate. The divergence between new and old inbreeding was higher in GUZ, showing a change in breeding policy in order to reduce the subdivision in this population. SIN showed drastic divergence between new and old inbreeding in the early 2000s, probably related to greater genetic exchange between herds due to the implementation of the progeny test. The same applies to the GIR breed. NEL and TAB showed smooth peaks in inbreeding increased over the years. This shows less abusive use of some individuals for reproduction in those breeds. In SIN, high peaks of increase in inbreeding showed the abusive use of some individuals for reproduction over two decades. This may have been influenced by the small number of animals available for reproduction on this breed compared with other breeds studied here. The small number of animals available for reproduction may also have influenced the mating decisions in IND in which also showed high peaks of increase in inbreeding. Because all breeds studied are submitted to the selection more or less effective for meat, milk or both via BLUP, the use of a wider range of sires can be recommended for all Zebu breeds as well as restriction in matings between close relatives, particulary in IND and SIN. In SIN and IND, the introduction of new individuals in the population could be beneficial to at least preserve the genetic diversity and to reduce the detrimental effects of inbreeding. In the case of SIN, the importation of individuals from India can be a rational decision. For GUZ, IND, SIN, and TAB a greater genetic exchange between herds may be advised in order to reduce the subdivision of the population. For BRA, GIR, and NEL the recommendation would be the maintenance of genetic exchanges between herds.

\section{Conclusion}

The monitoring of population structure, inbreeding and other related parameters has great potential to prevent major losses of genetic diversity in populations of Zebu cattle in Brazil. Almost all breeds studied undergo expansion in their census which, however, is not accompanied by the maintenance of genetic diversity. Problems were encountered in all breeds, but most of them can currently be considered less important. Thus, most Zebu breeds can deal with breeding programs using high selection intensities. Using the calculation method considered as the most accurate for pedigree analysis when some population substructure exists, except SIN, had effective population size greater than 100 . The most common problems were the presence of tight bottlenecks in the pedigree, which were mainly due to the intensive use of few sires lines as parents and the high degree of population subdivision. Because all breeds studied are submitted to the selection more or less effective for meat, milk or both via BLUP, the use of a wider range of sires can be recommended for all Zebu breeds as well as restriction in matings between close relatives, particulary in IND and SIN. For GUZ, IND, SIN, and TAB a greater genetic exchange between herds may be advised in order to reduce the subdivision of the population. For BRA, GIR, and NEL the recommendation would be the maintenance of genetic exchanges between herds. Greater care should be taken in the case of the IND breed since its census was reduced drastically over the last few years, a fact favoring the occurrence of serious problems related to inbreeding. Although SIN presents problems due to high subdivision and possesses a relatively small census compared to other Zebu breeds, this population would have a promising future if its breeding policy were revised.

\section{Conflict of interest statement}

The authors warrant that there are no any conflicts of interests among authors and between authors and other people, institutions or organizations.

\section{Acknowledgments}

We are indebted to Brazilian Association of Zebu Breeders (ABCZ) for providing access to the database used in this study. This work was funded by Fundação de Amparo à Pesquisa do Estado de Mato Grosso (FAPEMAT) - No. 321353/2012.

\section{Appendix A. Supplementary material}

Supplementary data associated with this article can be found in 
the online version at http://dx.doi.org/10.1016/j.livsci.2016.02.002.

\section{References}

Ballou, J.D., Lacy, R.C., 1995. Identifiyng genetically important individuals for management of genetic variation in pedigreed populations. In: Ballou, J.D., Gilpin, M., TJ, F. (Eds.), Population Management for Survival and Recovery. Columbia University Press, New York, pp. 76-111.

Berg, P., Nielsen, J., Sørensen, M.K., 2006. EVA: realized and predicted optimal genetic contributions. CD-ROM Communication 27-09. In: Proceedings of the 8th World Congress on Genetics Applied to Livestock Production, Belo Horizonte, Brazil.

Boichard, D., 2002. PEDIG: a fortran package for pedigree analysis suited for large populations. CD-ROM Communication 19-23. In: Proceedings of the 7th World Congress on Genetics Applied to Livestock Production, Montpellier, France.

Boichard, D., Maignel, L., Verrier, E., 1997. The value of using probabilities of gene origin to measure genetic variability in a population. Genet. Sel. Evol. 29, 5-23.

Caballero, A., Toro, M.A., 2000. Interrelations between effective population size and other tools for management of conserved populations. Genet. Res. 75, 331-343.

Caires, D.N., Malhado, C.H.M., Souza, L.D., Neto, M.R.T., Carneiro, P.L.S., Martins, R., 2012. Tabapua breed in Northeastern Brazil: genetic progress and population structure. Rev. Bras. Zootec. 41, 1858-1865.

Carneiro, P.L.S., Malhado, C.H.M., Martins, R., Carneiro, A.P.S., Silva, F.F.E., Torres, R. D., 2009. The Indubrasil breed in the Brazilian Northeast: breeding and population structure. Rev. Bras. Zootec. 38, 2327-2334.

Cervantes, I., Goyache, F., Gutiérrez, J.P., 2008. Ratio between inbreeding and coancestry rates as a measure of population subdivision. Preliminary results. ITEA-Inf. Tec. Econ. Ag 104, 303-307.

Cervantes, I., Goyache, F., Molina, A., Valera, M., Gutierrez, J.P., 2011. Estimation of effective population size from the rate of coancestry in pedigreed populations. J. Anim. Breed. Genet. 128, 56-63.

Colleau, J.J., Sargolzaei, M., 2008. A proximal decomposition of inbreeding, coancestry and contributions. Genet. Res. 90, 191-198.

Faria, F.J.C., Vercesi, A.E., Madalena, F.E., Josahkian, L.A., 2001. Population parameters of the registered Red Sindi in Brazil. Rev. Bras. Zootec. 30, 1989-1994.

Faria, F.J.C., Vercesi, A.E., Madalena, F.E., Josahkian, L.A., 2002. Pedigree analysis in the Brazilian zebu breeds. CD-ROM Communication 26-29. In: Proceedings of the 7th World Congress on Genetics Applied to Livestock Production, Montpellier, France.

Faria, F.J.C., Vercesi Filho, A.E., Madalena, F.E., Josahkian, L.A., 2009. Pedigree analysis in the Brazilian Zebu breeds. J. Anim. Breed. Genet. 126, 148-153.

Faria, L.C., Queiroz, S.A., Vozzi, P.A., Lobo, R.B., Magnabosco, C.D., Oliveira, J.A., 2010 Genetic variability detection in Brahman cattle in Brazil trough pedigree analysis. Pesqui. Agropecu. Bras. 45, 1133-1140.

González-Recio, O., López de Maturana, E., Gutiérrez, J.P., 2007. Inbreeding depression on female fertility and calving ease in Spanish dairy cattle. J. Dairy Sci. 90, 5744-5752.

Gutiérrez, J.P., Cervantes, I., Goyache, F., 2009. Improving the estimation of realized effective population sizes in farm animals. J. Anim. Breed. Genet. 126, 327-332.

Lacy, R.C., 1989. Analysis of founder representations in pedigrees: founder equivalents and founder genome equivalents. Zool. Biol. 8, 111-123.

Lacy, R.C., 1995. Clarification of genetic terms and their use in the management of captive populations. Zoo Biol. 14, 565-578.
Leroy, G., Mary-Huard, T., Verrier, E., Danvy, S., Charvolin, E., Danchin-Burge., C., 2013. Methods to estimate effective population size using pedigree data: examples in dog, sheep, cattle and horse. Genet. Sel. Evol. 45, 1.

Maignel, L., Boichard, D., Verrier, E., 1996. Genetic variability of French dairy breeds estimated from pedigree information. Interbull Bull. 14, 49-54.

Malhado, C.H.M., Carneiro, P.L.S., Martins, R., Azevedo, D.M.M.R., 2009. Genetic and populational background of Pure Nelore cattle breed in Brazilian Northeastern Sertão. Pesqui. Agropecu. Bras. 44, 713-718.

Peixoto, M.G.C.D., Poggian, C.F., Verneque, R.S., Egito, A.A., Carvalho, M.R.S., Penna, V.M., Bergmann, J.A.G., Viccini, L.F., Machado, M.A., 2010. Genetic basis and inbreeding in the Brazilian Guzerat (Bos indicus) subpopulation selected for milk production. Livest. Sci. 131, 168-174.

Perez, O.'Brien, Mészáros, G., Utsunomiya, Y.T., Sonstegard, T.S., Garcia, J.F., Van Tassell, C.P. Carvalheiro, R., da Silva, M.V.B., Sölkner, J, 2014a. Linkage disequilibrium levels in Bos indicus and Bos taurus cattle using medium and high density SNP chip data and different minor allele frequency distributions. Livest. Sci. 166, 121-132.

Perez, O.'Brien, Utsunomiya, Y.T., Mészáros, G., Bickhart, D.M., Liu, G.E., Van Tassell, C.P., Sonstegard, T.S., da Silva, M.V.B., Garcia, J.F., Sölkner, J., 2014b. Assessing signatures of selection through variation in linkage disequilibrium between taurine and indicine cattle. Genet. Sel. Evol. 46, 19.

Perez O’Brien, A.M., Höller, D., Boison, S.A., Milanesi, M., Bomba, L., Utsunomiya, Y. T., Carvalheiro, R., Neves, H.H.R., da Silva, M.V.B., Van Tassell, C.P., Sonstegard, T. S., Mészáros, G., Ajmone-Marsan, P., Garcia, J.F., Sölkner, J., 2015. Low levels of taurine introgression in the current Brazilian Nelore and Gir indicine cattle populations. Genet. Sel. Evol. 47, 31.

Reich, D.E., Cargill, M., Bolk, S., Ireland, J., Sabeti, P.C., Richter, D.J., Lavery, T., Kouyoumjian, R., Farhadian, S.F., Ward, R., Lander, E.S., 2001. Linkage disequilibrium in the human genome. Nature 411, 199-204.

Reis Filho, J.C., Lopes, P.S., Verneque, R.S., Torres, R.A., Teodoro, R.L., Carneiro, P.L.S. 2010. Population structure of Brazilian Gir dairy cattle. R. Bras. Zootec. 39, 2640-2645.

Santana, M.L., Pereira, R.J., Bignardi, A.B., El Faro, L., Tonhati, H., Albuquerque, L.G., 2014. History, structure, and genetic diversity of Brazilian Gir cattle. Livest. Sci. $163,26-33$.

Sargolzaei, M., Iwaisaki, H., Colleau, J.J., 2006. CFC: a tool for monitoring genetic diversity. CD-ROM Communication 27-28. In: Proceedings of the 8th World Congress on Genetics Applied to Livestock Production, Belo Horizonte, Brazil

Stachowicz, K. Sargolzaei, M., Miglior, F., Schenkel, F.S., 2011. Rates of inbreeding and genetic diversity in Canadian Holstein and Jersey cattle. J. Dairy Sci. 94, 5160-5175.

Vercesi, A.E., Faria, F.J.C., Madalena, F.E., Josahkian, L.A., 2002a. Population structure of the registered Indubrasil cattle in Brazil. Arch. Latinoam. Prod. Anim. 10 86-92.

Vercesi, A.E., Faria, F.J.C., Madalena, F.E., Josahkian, L.A., 2002b. Population structure of the registered Tabapua cattle in Brazil. Arq. Bras. Med. Vet. Zootec. 54, 609-617.

Wright, S., 1969. Evolution and the genetics of populations. In: Theory of Gene Frequencies. Vol. 2. University of Chicago Press, Chicago, USA.

Zavarez, L.B., Utsunomiya, Y.T., Carmo, A.S., Neves, H.H.R., Carvalheiro, R., Ferencakovi, M., Pérez, O.’Brien, A.M., Curik, I., Cole, J.B., Van Tassell, C.P., da Silva, M.V.G.B., Sonstegard, T.S., Sölkner, J., Garcia, J.F., 2015. Assessment of autozygosity in Nellore cows (Bos indicus) through high-density SNP genotypes. Front. Genet. 6, 5 . 